\title{
THE IMPACT OF MOBILE APPLICATIONS ON MATERNITY EDUCATION: A QUANTITATIVE STUDY OF KENYA
}

\author{
Hussein Abdinoor Mohamed, Harrisburg University of Science and Technology, hmohamed@harrisburgu.edu \\ Chaza Abdul, Harrisburg University of Science and Technology, cabdul@harrisburgu.edu \\ Wenli Wang, Robert Morris University, wangw@rmu.edu \\ Nancy Mimm, Harrisburg University of Science and Technology, nmimm@harrisburgu.edu
}

\begin{abstract}
Maternal health mortality refers to death that occurs during pregnancy, pregnancy termination, at birth, or within the first two months of the birth. According to World Health Organization (2015), the average number of maternal deaths in sub-Saharan Africa was 239 for a population of 100,000 people, compared to 12 in the developed countries in 2015 despite that health organizations worldwide had aimed to reduce the maternal mortality ratio by 75\% from 1990 to 2015. To reduce maternal mortality in Africa, this research developed a mobile health application system that provided maternal health information and education to pregnant mothers in rural Kenya so that mothers could identify problems early on in their pregnancies. A quantitative survey of these mothers showed high satisfaction, usability, and systems effectiveness ratings of the mobile health system. These insights will benefit policy makers to promote mobile health to help improve maternal education and reduce maternal mortality.
\end{abstract}

Keywords: Mobile Health, Maternal Health Mortality, Maternity Education, Accessibility

\section{INTRODUCTION}

Maternal health mortality refers to death that occurs during pregnancy, pregnancy termination, at birth, or within the first two months of the birth. Kenya has one of the highest mortality rates in sub-Saharan Africa - for every 100,000 live births, a total of 488 deaths have been reported (Ziraba, et. al., 2009). Even though the number is lower than the average death of 688 per 100,000 live births in Africa (Ziraba, et. al., 2009), it is still quite high, especially in comparison to that of developed countries.

Although worldwide health organizations had aimed to reduce the maternal mortality ratio drastically from 1990 to 2015 by up to $75 \%$ (WHO, 2015), the reduction of maternal and child mortality rates in the developing countries, particularly sub-Saharan Africa, remains a huge challenge. For a population of 100,000 people, the average number of maternal deaths in sub-Saharan Africa was 239 in 2015, compared to 12 in the developed countries (WHO, 2015). On the other hand, it was estimated a total number of 4.2 million infants die during the first year after their births (WHO, 2015). The report also showed that over 90\% of maternal and child mortality occur in sub-Saharan Africa, and Kenya leads the pack in East Africa (WHO, 2015).

Maternal deaths are mainly due to complications related to pregnancy and childbirth. Severe bleeding, unsafe abortion, and sicknesses such as hypotensive disorders, malaria, hepatitis and anemia have often attributed to the increase in maternal and child mortality rates. According to the Kenya Health Survey (Kenya DHS, 2014), the Kenyan government identified several factors that have been stumbling blocks to reduce maternal health. The main two factors among them were lacking of knowledge in recognizing the danger signs in pregnancy and the lack of serious care during pregnancy, at child birth, or during the post-birth period (Anem, 2016).

Rapid advances in mobile, wireless, and sensing technologies have opened new opportunities in maternal healthcare. Mobile technology can be applied to improve surveillance and create awareness of dangers signs and symptoms among pregnant mothers. Innovative techniques can be used to enable mothers to report the danger signs and seek remedial actions or interventions in time to ensure their safety and that of their children.

Developing a mobile application system that provides maternal health information and knowledge to pregnant mothers can enhance maternal education and help identify problems early on in their pregnancy. To improve the quality of information shared to expectant mothers and to enhance their knowledge are part of service enhancement in the healthcare sector and one of the means to reduce maternal mortality. 


\section{Issues in Information Systems}

Volume 21, Issue 2, pp. 314-320, 2020

This research is to examine the efficacy of mobile applications in reducing maternal mortality in sub-Saharan African particularly Kenya where the basic healthcare is not easily accessible. The research aims to answer the following research questions specifically:

RQ1. Can mobile applications enhance maternal education to reduce mortality?

RQ2. Are mothers satisfied with the mobile health?

RQ3. Are mobile health applications easy to use by mothers?

RQ4. Are mobile health systems effective to enhance maternal education?

The findings of this research will benefit various stakeholders. Researchers can gain insights how technology helps reduce maternal mortality. For policy makers in the governmental and non-governmental agencies, the findings will provide a basis for policymaking and technology innovations in maternal healthcare.

\section{LITERATURE REVIEW}

This section provides the brief literature review on maternal/child health and mobile health in Africa specifically. The review also addresses the challenges and limitations witnessed in similar studies.

\section{Maternal and child healthcare}

There is a huge gap between maternal healthcare in the developed countries and that of the third world countries. Technological advancements in the developed countries are more sophisticated and healthcare facilities are of the higher standards. However, maternal deaths are also largely due to the lack of information and access to healthcare services. Literacy levels contribute to the disparities between the developed and developing countries. According to Anem (2010), a significant number of maternal deaths during pregnancy in sub-Saharan Africa can be avoided. For instance, in Kenya, mothers with high literacy levels were 2.17 times more likely to be fully immunized as compared to those who lacked any formal education (Abuya et. al., 2011).

\section{Mobile applications in healthcare}

Mobile health (mHealth) solutions are basically health-related technical applications targeting mobile users in remote areas where access to Internet connection is non-existent or difficult. The use of mobile applications in the healthcare industry in sub-Saharan Africa is on the rise (Luseka, 2015).

According to the World Health Organization (2015), the rise of mHealth solutions is largely attributed to the increased usage of mobile devices. For example, Nigeria has successfully adopted mobile devices as communication tools to connect pregnant mothers in hospitals and delivery facilities located in remote villages in a bid to reduce maternal mortality. Since successful deployment of the project, maternal mortality rate has reduced by $47 \%$ and a reduction of child mortality by $26 \%$ (WHO, 2015).

Mobile devices usage has been on the rise in Kenya as well. In the 2015-2016 fiscal year, the mobile penetration level in Kenya was steadily increasing and hit the 88\% penetration rate (Luseka, 2016). The subscription number increased from 36.1 million to 37.8 million. The number of Internet users grew by $10 \%$.

\section{Problems and challenges}

Mobile applications used in health sector have their fair share of challenges. Abuya et. al. (2011) identified several challenges faced when developing and implementing mobile application systems in the developing countries:

1) There were issues with reliable mobile phone signal coverage in the rural areas. These areas were remote and not properly served with telephone coverage. Even for those areas with coverage, the signal was very weak and unreliable.

2) There was a lack of basic knowledge to read and operate a mobile phone. Not to mention that people in the remote rural areas often lack the basic literacy skills to read and write. 
3) There was a lack of government support when managing mHealth projects. Agencies mandated to run and manage mHealth projects in the developing countries often did not provide sufficient logistics support, data or even personnel needed in these projects (Martinez, et.al. 2018; Darwinkel, et.al. 2018).

4) There were financial challenges when undertaking mHealth projects in the third-world countries. Therefore, there was a need to design technical systems that are inexpensive to operate and maintain for both the users and the projects owners (Tama, et.al., 2018).

\section{RESEARCH METHODOLOGY}

The study was conducted in Habaswein, a remote village in the north-eastern province of Kenya in the county of Wajir. The village is characterized by high level of poverty and low quality of health services. Pregnant mothers in this region have little or no access of healthcare services. The government hospitals lack medicines and personnel required to provide adequate healthcare services. The village is also characterized by low levels of literacy and expectant mothers lack vital information on maternal and postnatal care.

The research applied design science approach and focus group studies to develop a mobile health system. The feedbacks obtained from the observations on how the system was used and from the qualitative interviews were used to improve the application and to fine-tune the software requirement and features of the mobile application.

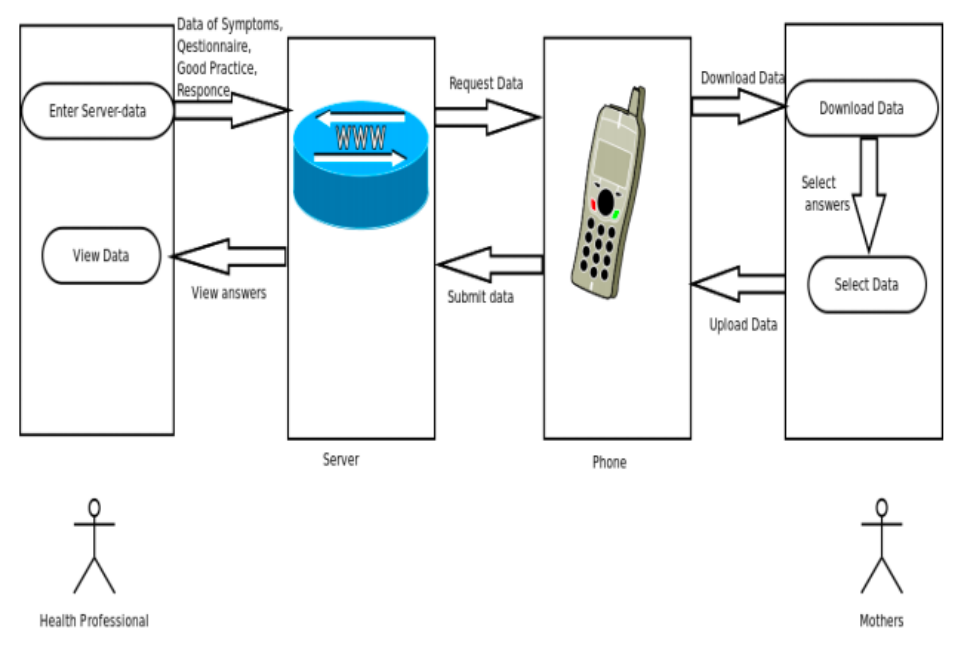

Figure 1. The mobile health system for maternal health

Table 1 shows that the system architecture for the final mobile health system for maternal health. There are two major technical components: the server and the client (e.g., mobile phone). There are two major stakeholders, the health professionals and mothers. Health professionals submit data into server such as symptoms of diseases, good practices, and questions and answers data. Mothers, on the other hand, use their phones to access to the maternal health information. Essentially, their phones would download data. After reviewing maternal health information, mothers have the options to upload their data to the server. Health practitioners then can view the mothers' data and questions and respond to them. The design ensures the proper information flow throughout the system.

The population of interest were expectant mothers and mothers with children under two years of age from the Habaswein village in Wajir county, Kenya. A quantitative survey was issued to a sample of expectant mothers and mothers with infants who have used the mobile health system. The questionnaire consisted of both structured and open-ended questions. The structured evaluations were conducted in the following areas: 
1) Satisfaction of using the system

2) Usability of the system; and

3) Effectiveness of the system.

The respondents were asked to evaluate the above three areas of the system by using a scale from 1-5 representing "strongly disagree" to "strongly agree." Open-ended questions were related to these three areas as well where respondents can provide unstructured feedback such as challenges in usability, etc.

\section{RESULTS}

As shown in the Table 1 below, the total number of questionnaires sent were 135. Among them, 112 responded to the survey and only 23 did not respond or submitted the survey in a correct manner. The response rate is high, which is about $83 \%$ (see Table 1 ).

Table 1: Survey response rate

\begin{tabular}{|c|c|c|}
\hline Response Rate & Frequency & Percentage \\
\hline Response & 112 & 83 \\
\hline Non response & 23 & 17 \\
\hline Total & $\mathbf{1 3 5}$ & $\mathbf{1 0 0}$ \\
\hline
\end{tabular}

The Table 2 show that out of the total 112 respondents, 65 of them strongly agreed or agreed to the fact that they were satisfied with the system. A meagre 27 out of the 112 were not satisfied with the system. The average system satisfaction rate was 3.37 out of 5 (5: Strongly Agree). From the Table 2 below, it can be seen that around 58\% of the people were satisfied with the system in general. This goes to show that most of the people were satisfied with the mobile health system's robustness and ease of use. The number of users not satisfied with the system could be attributed to the high illiteracy levels and the lack of the technical knowhow needed to operate mobile systems.

Table 2. System satisfaction

\begin{tabular}{|c|c|c|}
\hline Rating & Frequency & Percentage \\
\hline Strong Agree & 20 & 18 \\
\hline Agree & 45 & 40 \\
\hline Not sure & 20 & 9 \\
\hline Disagree & 10 & 15 \\
\hline Strongly Disagree & 17 & $\mathbf{1 0 0}$ \\
\hline Total & $\mathbf{1 1 2}$ & \\
\hline
\end{tabular}

The next evaluation was to test the ease of use of the mobile health system. According to Ziraba et. al. (2009), usability refers to the degree to which a piece of software system can be used by certain consumers and achieve the set-out objectives with effectiveness, efficiency, and satisfaction in a quantified context of use. From the results shown in Table 3, it could be seen that a huge number of people generally found the system easy to use. A total of 80 users out of the 112 either strongly agreed or agreed that the system is easy to use and they could easily get the 


\section{Issues in Information Systems}

Volume 21, Issue 2, pp. 314-320, 2020

best out the system without any hurdles or usability issues. The average usability rating was 3.66 out of 5 (5: Strongly Agree). This high usability rating can be attributed to the fact that the mobile health system was designed in a simple way. A clean easy-to-use user interface was employed. The system also had a very intuitive navigation system allowing users to navigate throughout the system without any hurdles.

Table 3. Usability

\begin{tabular}{|c|c|c|}
\hline Rating & Frequency & Percentage \\
\hline Strong Agree & 30 & 27 \\
\hline Agree & 50 & 95 \\
\hline Not sure & 10 & 7 \\
\hline Disagree & 8 & 13 \\
\hline Strongly Disagree & 14 & $\mathbf{1 0 0}$ \\
\hline Total & $\mathbf{1 1 2}$ & 9 \\
\hline
\end{tabular}

Table 4 shows that over $86 \%$ of the users found that the system was effective and added value to their lives. The pregnant mothers were very satisfied with reproductive health education they were receiving from the health practitioners enrolled in the system. The average system effective rating is 4.17 out of 5 (5: Strongly Agree).

\section{Table 4. System effectiveness}

\begin{tabular}{|c|c|c|}
\hline Rating & Frequency & Percentage \\
\hline Strong Agree & 56 & 50 \\
\hline Agree & 40 & 36 \\
\hline Not sure & 1 & 8 \\
\hline Disagree & 9 & 5 \\
\hline Strongly Disagree & 6 & $\mathbf{1 0 0}$ \\
\hline Total & $\mathbf{1 1 2}$ & 1 \\
\hline
\end{tabular}

\section{DISCUSSIONS}

In summary, mobile health application can be developed to enhance maternal education to reduce maternal mortality. The majority of the respondents was satisfied with the mobile application system and found it easy to use. The mothers felt that the mobile system was effective in dissemination of information. $50 \%$ of the respondents strongly felt that information they got effectively helped them during their pregnancy.

This research resulted in the following practical implications. It is recommended that: 1) It is important to improve infrastructure to increase accessibility in rural areas hence enhancing the sharing of information. And 2) It would be 
better to localize the mobile applications in the local languages and use voice recording to share information due to high illiteracy levels in the rural areas.

In general, the research was successful. However, several factors were identified as the major stumbling blocks while conducting the research. These factors are: 1) high illiteracy levels among the women; 2) lack of smartphones in rural areas; 3) usability issues among the older mothers; and 4) the high cost of maintaining the system. These factors are consistent with the findings of Abuya et. al. (2011).

This research was only in one rural county in Kenya. It is recommended to conduct further research in bigger cities and in other counties as well in order to reach stronger conclusions on the effectiveness of similar kind of mobile health systems on maternity education.

\section{SUMMARY}

This research shows that mobile health applications can improve the sharing of vital information about maternal health and increase the awareness and knowledge about maternal health among expectant mothers, even in rural areas of developing countries. Simplicity and usability of great user experience are key to ensure the high uptake of mobile health among rural mothers. Rural mothers who have used mobile applications are in general satisfied with these applications and found the system effective.

The finding of this research are important to different stakeholders in the healthcare industry. It not only helps researchers and scholars to design better mobile applications to enhance maternity education but also assists policy makers and governmental/non-governmental agencies in their policy makings and technology innovations in the healthcare sector.

\section{REFERENCES}

Abuya, B.A., Onsomu, E.O., Kimani, J.K., \& Moore, D. (2011). Influence of maternal education on child immunisation and stunting in Kenya. Maternal and Child Health Journal, 15, 1389-1399.

Luseka, B. (2016). An evaluation of Toto-Health mobile platform on material and child healthcare in Kenya. School of Journalism and Mass Communication. Retrieved from http://erepository.uonbi.ac.ke/bitstream.

Darwinkel M. C., Nduru J. M., Nabie R.W., \& Aswani J. A. (2018). Evaluating the role of clinical officers in providing reproductive health services in Kenya. Human Resource Health, 16(1), 31.

Anam, A. F. (2016). An evaluation of Kenya PrEP Communication campaign 'JIPENDE JIPrEP' on the use of preexposure Prophylaxis (PrEP) among young women in Embakasi, Nairobi, Kenya. University of Nairobi. Retrieved from http://www.erepository.uonbi.ac.ke/handle/11295/108911

Kenya DHS (2014). Kenya demographic and health survey. Retrieved from https://www.dhsprogram.com/pubs/pdf/FR308/FR308.pdf

Martinez, B., Ixen, E. C., Hall-Clifford, R., Juarez, M., Miller, A. C., Francis, A., Valderrama, C. E., Stroux, L., Clifford, G. D., \& Rohloff, P. (2018). mHealth intervention to improve the continuum of maternal and perinatal care in rural Guatemala: a pragmatic, randomized controlled feasibility trial. Reproductive health, 15(1), 120. https://doi.org/10.1186/s12978-018-0554-z 
Tama E., Molyneux S., Waweru E., Tsofa B., Chuma J. and Barasa E. (2018). Examining the implementation of the free maternity services policy in Kenya: a mixed methods process evaluation. International Journal of Health Policy Management. 7(7), 603-163.

World Health Organization. (2011). mHealth: new horizons for health through mobile technologies. Global Observatory for eHealth Series, 3. Retrieved from

https://www.who.int/goe/publications/goe_mhealth_web.pdf

World Health Organization. (2015) Trends in maternal mortality: 1990-2015: estimates from WHO, UNICEF, UNFPA, World Bank Group and the United Nations Population Division. Retrieved from https://www.afro.who.int/sites/default/files/2017-05/trends-in-maternal-mortality-1990-to-2015.pdf

World Health Organization. (2019) Trends in maternal mortality: 2000-2017: estimates by WHO, UNICEF, UNFPA, World Bank Group and the United Nations Population Division. Retrieved from https://www.unfpa.org/sites/default/files/pub-pdf/Maternal_mortality report.pdf

Ziraba, A. K., Madise, N., Mills, S., Kyobutungi, C., \& Ezeh, A. (2009). Maternal mortality in the informal settlements of Nairobi city: what do we know? Reproductive Health, 6(6). 